\title{
Xe Ion Irradiation-Induced Microstructural Evolution and Hardening Effect of Nickel-Base Superalloy
}

\author{
Yu Hou $\mathbb{D}$, ${ }^{1,2}$ DeHui Li $\mathbb{D},{ }^{1}$ YanLing Lu $\mathbb{D}^{1},{ }^{1}$ HeFei Huang, ${ }^{1}$ WeiGuo Yang $\mathbb{D},^{2}$ \\ and RenDuo Liu ${ }^{1}$ \\ ${ }^{1}$ Shanghai Institute of Applied Physics, Chinese Academy of Sciences, Shanghai 201800, China \\ ${ }^{2}$ School of Materials of Science and Engineering, Jiangsu University of Science and Technology, Zhenjiang 212000, China \\ Correspondence should be addressed to DeHui Li; lidehui@sinap.ac.cn, YanLing Lu; luyanling@sinap.ac.cn, and \\ WeiGuo Yang; ywgjskd@163.com
}

Received 31 January 2021; Revised 8 October 2021; Accepted 9 October 2021; Published 19 November 2021

Academic Editor: Arkady Serikov

Copyright (C) $2021 \mathrm{Yu}$ Hou et al. This is an open access article distributed under the Creative Commons Attribution License, which permits unrestricted use, distribution, and reproduction in any medium, provided the original work is properly cited.

The nickel-base superalloy Hastelloy $\mathrm{N}$ was irradiated using $1 \mathrm{MeV} \mathrm{Xe}^{20+}$ and $7 \mathrm{MeV} \mathrm{Xe}^{26+}$ ions with displacement damage ranging from $0.5 \mathrm{dPa}$ to $10 \mathrm{dPa}$ at room temperature (RT). The irradiated Ni-based superalloy was characterized with transmission electron microscopy (TEM), XRD, and nanoindenter to determine the changes in microstructural evolution and nanoindentation hardness. The TEM results showed that ion irradiation induced a large number of defects such as black spots and corrugated structures and the second phase was rapidly amorphized after being irradiated to a fluence of $0.5 \mathrm{dPa}$. The XRD results showed that the Hastelloy $\mathrm{N}$ alloy sample did not undergo lattice distortion after ion irradiation. An obvious irradiation hardening phenomenon was observed in this study, and the hardness increased with Xe ion fluence. The pinning effect in which the defects can become obstacles to the free movement of dislocation may be responsible for the irradiation-induced hardening.

\section{Introduction}

Nuclear energy will play a more important role in meeting future energy needs for the fast-growing energy demands and concerns about climate changes [1]. The molten salt reactor (MSR), one of the six most promising generation IV nuclear reactor systems, has attracted increasing interest for its incomparable advantages: high inherent safety, reliability, higher power generation efficiency, etc. $[2,3]$. However, the development and deployment of MSR systems are hindered by the structural materials. The structural alloys which must be subjected to extremely harsh environments involving high temperature, high neutron doses, and strong molten salt corrosion [4-7]. Thanks to its excellent corrosion resistance and adequate high-temperature strength, the nickel-based Hastelloy $\mathrm{N}$ alloy, which was developed by Oak Ridge National Laboratory (ORNL) in the 1960s [8], is still considered as the most promising candidate for the structural materials of MSR [9].

As we know, neutron bombardment can induce a microstructural evolution of structural materials during the operation of the reactor, which can degrade their mechanical performances [10-12]. Hence, the evaluation of irradiation damage in structural materials is particularly important. The ion irradiation has advantages such as the easier control of irradiation parameters, reduction of cost and rapid damage production to neutron irradiation, and the high dose and high flux ion irradiation [13-19].

In this study, xenon ions were selected to irradiate the Hastelloy $\mathrm{N}$ alloy for their significant displacement damage within the material, which is similar to the neutron irradiation damage behavior. Some thin-foil and bulk specimens of Hastelloy $\mathrm{N}$ alloy were irradiated, respectively, with $1 \mathrm{MeV} \mathrm{Xe} e^{20+}$ ions and $7 \mathrm{MeV} \mathrm{Xe} e^{26+}$ ions, at different fluences. The bulk and thin-foil specimens were characterized by nanoindentation and transmission electron microscopy (TEM) to study the changes. However, the ion irradiationinduced mechanical properties are difficult to be tested owing to the limitation of ion penetration depth, normally from nanometers to micrometers. In recent years, the 
nanoindentation test has been widely used to study the irradiation hardening of the reactor structural materials $[20,21]$, thanks to its powerful capability on thin-layer nanohardness measurement [22]. The correlation between the irradiation-induced formation of defects and irradiation-induced hardening was quantitatively analyzed.

\section{Experimental}

The Hastelloy $\mathrm{N}$ alloy used was subjected to cold-rolling and annealing treatment (for $6 \mathrm{~min}$ at $1177^{\circ} \mathrm{C}$, water quenching). The overall chemical composition of Hastelloy $\mathrm{N}$ alloy is provided in Table 1. The bulk materials were cut into several plates with a dimension of $10 \times 10 \times 1 \mathrm{~mm}^{3}$ using a wire electrode and polished with silicon carbide paper from grade 800 to 2000 , by means of vibration polishing (including nanoalumina powder $\sim 20 \mathrm{~nm}$ ), to obtain a mirror-like surface. These mechanically polished plates were subsequently prepared by electropolishing at $36 \mathrm{~V}$ for about $10 \mathrm{~s}$ in an aqueous solution of $50 \% \mathrm{H}_{2} \mathrm{SO}_{4}$ and $40 \%$ glycerin under the temperature of $0^{\circ} \mathrm{C}$, followed by ultrasonic cleaning using alcohol and deionized water sequentially. Several specimens were prepared as disks of $3 \mathrm{~mm}$ in diameter for TEM studies. Thin foils were obtained by mechanical thinning of the disks down to $100 \mu \mathrm{m}$, followed by twin-jet electropolishing, with an alcoholic solution of $5 \% \mathrm{HClO}_{4}$.

The as-prepared samples were irradiated at room temperature (RT), on the $320 \mathrm{KV}$ Highly Charged Ions Research Platform, at the Institute of Modern Physics, Chinese Academy of Sciences (HCIRP-IMP-CAS) [23]. The bulk samples were irradiated with $7 \mathrm{MeV} \mathrm{Xe}{ }^{26+}$ ions to fluences of $0,1.25 \times 10^{14}, 5.0 \times 10^{14}, 1.25 \times 10^{15}$, and $2.5 \times 10^{15}$ ions $/ \mathrm{cm}^{2}$ equivalent to a maximum damage of $0,0.5,2,5$, and $10 \mathrm{dPa}$. For the thin-foil specimens, the irradiation of $1 \mathrm{MeV} \mathrm{Xe}^{20+}$ ions was chosen to make sure that the irradiation damage depth is suitable to the thickness of the thin area (less than $150 \mathrm{~nm})$.

The ion irradiation-induced microstructural evolution of the Hastelloy $\mathrm{N}$ alloy samples was characterized by a FEI Tecnai G2 F20 transmission electron microscope with an accelerating voltage of $200 \mathrm{kV}$. In order to reveal the correlation between the changes in mechanical properties and the microstructural evolution, the nanoindentation hardness of the un-irradiated and irradiated samples was measured on a G200 nanoindenter instrument. The experimental hardness was determined from the analysis of load-displacement $(\mathrm{P}-\mathrm{h})$ curves using the Oliver and Pharr method [24, 25]. In this study, five single indents were performed for each sample to ensure the reliability of the measurements.

\section{Results and Discussion}

3.1. TEM Characterization. Bright-field TEM micrographs of the un-irradiated Hastelloy $\mathrm{N}$ sample are shown in Figure 1. Except for some dislocation lines, almost no other defects were observed in the un-irradiated sample. Figure 2 shows the TEM micrographs of Hastelloy $\mathrm{N}$ after ion irradiation to $0.5,2,5$, and $10 \mathrm{dPa}$. Irradiating to a fluence equivalent to $0.5 \mathrm{dPa}$ caused the disappearance of the
TABLE 1: Chemical composition of the Hastelloy $\mathrm{N}$ superalloy (wt. \%).

\begin{tabular}{lcccccccccc}
\hline Elements & $\mathrm{Ni}$ & $\mathrm{Mo}$ & $\mathrm{Cr}$ & $\mathrm{Fe}$ & $\mathrm{Mn}$ & $\mathrm{Si}$ & $\mathrm{Al}$ & $\begin{array}{c}\mathrm{Ti} / \\
\mathrm{Cu} /\end{array}$ & $\mathrm{C}$ \\
$\mathrm{Co}$ & \\
\hline $\begin{array}{l}\text { Hastelloy N } \\
\text { alloy }\end{array}$ & 71.0 & 17.1 & 6.9 & 3.9 & 0.51 & 0.27 & 0.19 & 0.01 & 0.057 \\
\hline
\end{tabular}

original dislocations in the alloy and appearance of obvious black spots of about $5 \sim 10 \mathrm{~nm}$ in the alloy. These black spots may be dislocation loops $[26,27]$, stacking fault tetrahedra (SFTs) [28], or defect clusters $[29,30]$. When the irradiation fluence reached $2 \mathrm{dPa}$, corrugated-like structures began to gradually form, as shown in Figure 2(b), and this stage was the initial stage of the corrugated structure. At $5 \mathrm{dPa}$, black spots started to mix with the corrugated-like structures. Figures 2(c) and 2(d) show that the morphology of the corrugated-like structure became more and more obvious with the increase in ion fluence, which means that the corrugated structure is the final formation stage of the irradiated superalloy.

To study the characteristics of the irradiated Hastelloy N alloy, the element mapping was performed to investigate the atomic migration and element distribution of the alloy after irradiation (Figure 3). Figure 3(a) shows the TEM morphology results of the alloy viewed along the $\langle 110\rangle$ axis, and Figures $3(\mathrm{~b})-3(\mathrm{~g})$ show the element mapping results of the corrugated-like structure. It can be seen that the ion irradiation has caused a huge change in the alloy and some elements are unevenly distributed in the alloy (e.g., Figure 3(b)), but the other elements are still uniformly distributed in the alloy (e.g., Figures $3(\mathrm{c})-3(\mathrm{~g})$ ), which indicate that $\mathrm{Xe}$ ion irradiation can make some specific elements to segregate. Considering that irradiation will only make the sample surface smoother, but not make the flat surface more uneven, in this respect, the change of elements may be due to the element segregation and may not be caused by the uneven surface.

Ion irradiation affects the alloy structure in many aspects. Here, the second phase of the alloy after ion irradiation was also studied, as shown in Figure 4. Figure 4(a) shows that the second phase in the un-irradiated alloy has a face-centered cubic structure. Its lattice constant $a$ was found to be $1.09 \mathrm{~nm}$, which is consistent with the $\mathrm{M}_{6} \mathrm{C}$, reported in Hastelloy $\mathrm{N}$ alloy by Oak Ridge National Laboratory (ORNL) [31]. However, the $\mathrm{M}_{6} \mathrm{C}$ can be rapidly amorphized with a lower fluence of $0.5 \mathrm{dPa}$ (Figure 4(b)) and the amorphous state is still stable with a higher fluence (Figures 4(c)-4(e)). This is different from the MSRE results that the neutron irradiation would accelerate the formation of small $\mathrm{M}_{6} \mathrm{C}$ along the grain boundaries and would not change the structure of $\mathrm{M}_{6} \mathrm{C}$.

It was reported in the literature that irradiation will cause the physical, chemical, and mechanical properties of the alloy grain boundaries to be reduced [32]. In this study, we analyzed the element distribution of the grain boundaries before and after ion irradiation (Figures 5 and 6). However, 


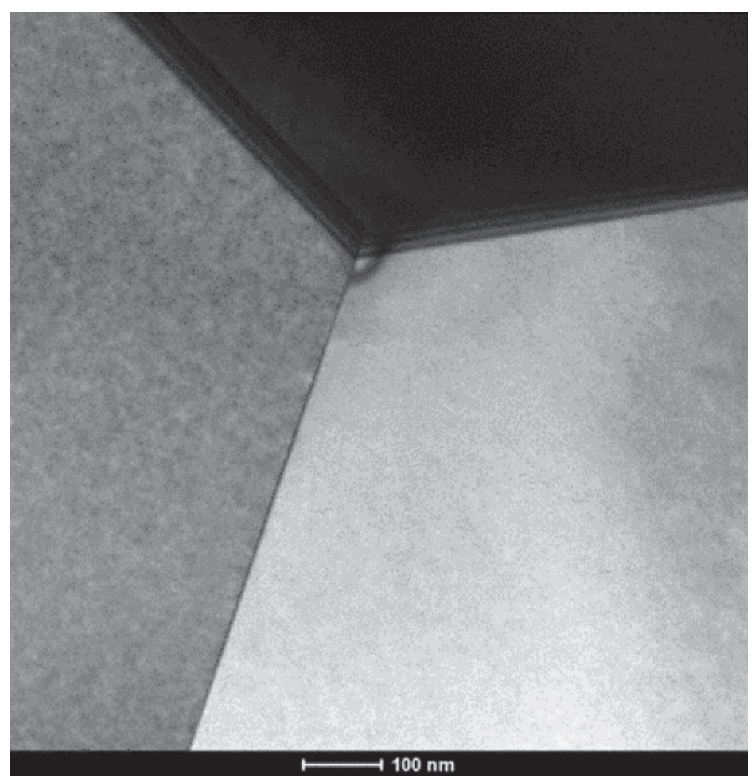

FIgURE 1: TEM micrographs of un-irradiated Hastelloy N.

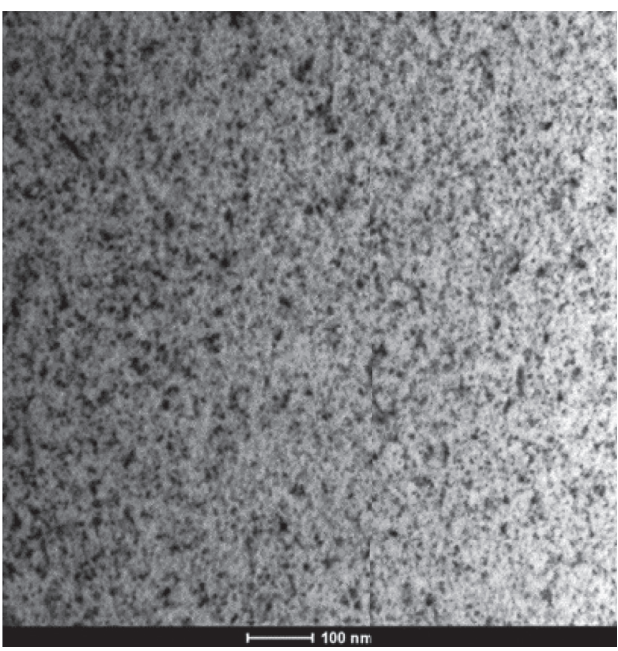

(a)

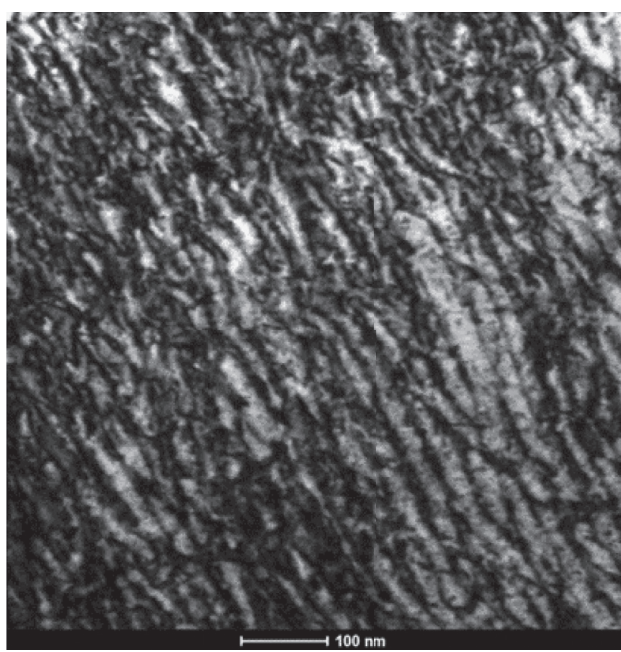

(c)

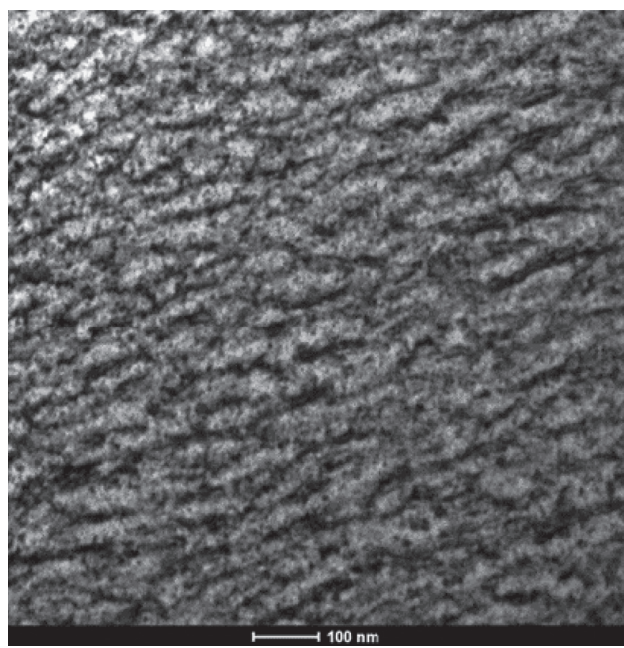

(b)

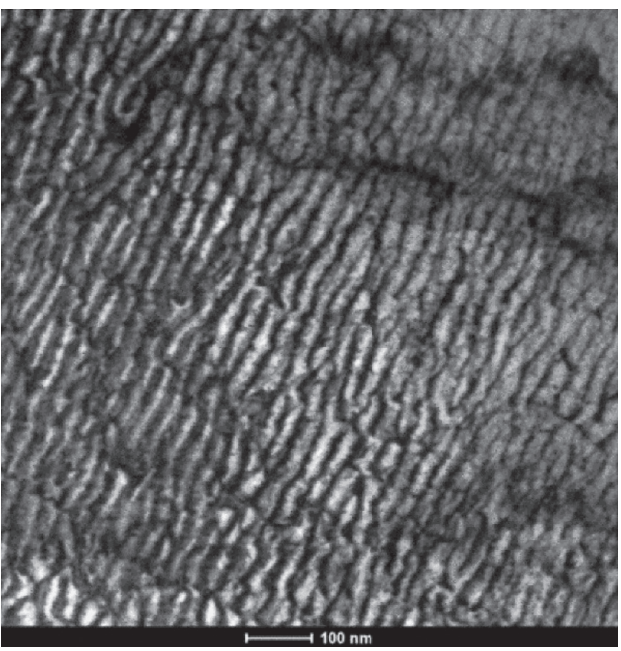

(d)

Figure 2: TEM micrographs of Hastelloy $\mathrm{N}$ after ion irradiation to a fluence equivalent to (a) $0.5 \mathrm{dPa}$, (b) $2 \mathrm{dPa}$, (c) $5 \mathrm{dPa}$, and (d) $10 \mathrm{dPa}$. 


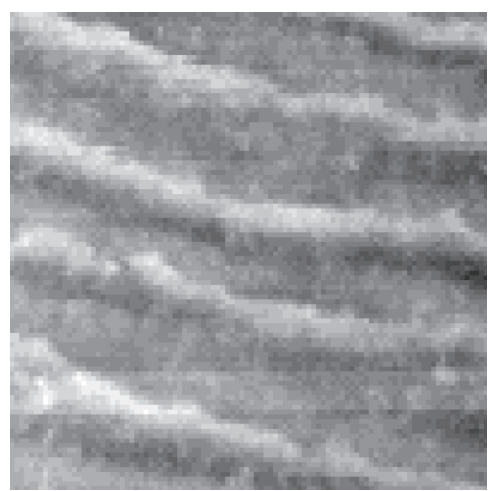

(a)

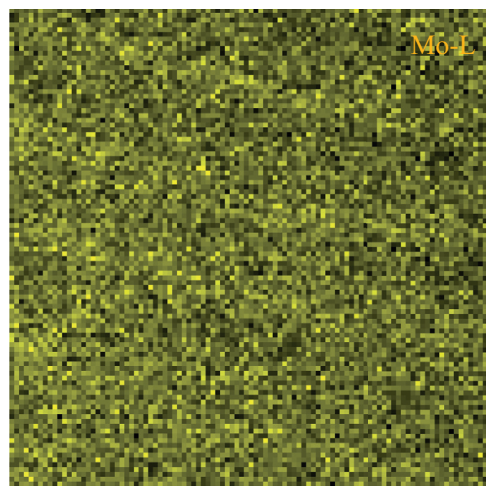

(d)

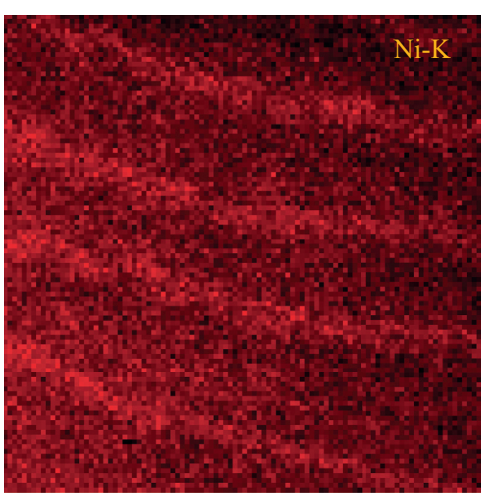

(b)

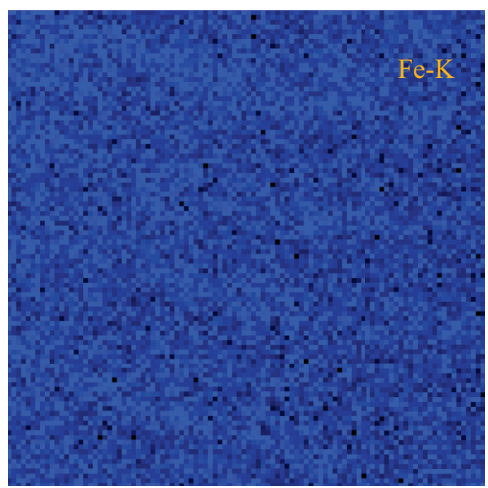

(e)

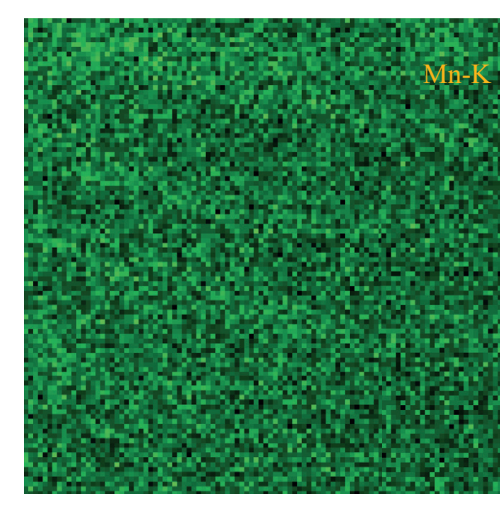

(g)

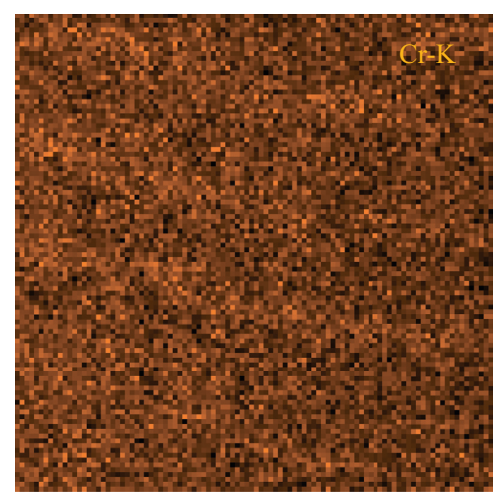

(c)

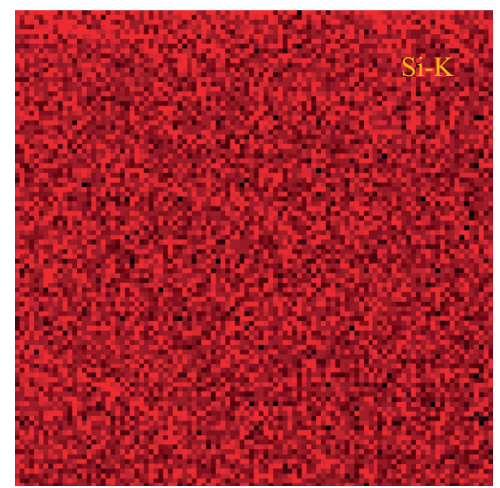

(f)

FIgURe 3: Morphology and element mapping results of Hastelloy $\mathrm{N}$ along the $<110>$ belt axis after ion irradiation (10 dPa).

the results showed that there was no obvious phenomenon of element segregation along the grain boundaries.

To investigate the elemental difference between the second phase and the matrix before and after irradiation, a line scan analysis was performed between the second phase and the matrix using transmission electron microscopy (Figures 7 and 8). The results of the line scan showed that the second phase was enriched with $\mathrm{Mo}$ and $\mathrm{Si}$, while the $\mathrm{Ni}, \mathrm{Fe}$, and $\mathrm{Cr}$ contents in the matrix were relatively high; as for $\mathrm{Mn}$, it was relatively uniformly distributed in the second phase and the matrix.

3.2. $X R D$. The alloy samples were analyzed by the grazing incidence X-ray diffraction (GIXRD) test method. Figure 9 compares the strongest diffraction peaks of un-irradiated and irradiated samples. It can be seen that the positions of the diffraction peak of the sample have inconspicuous deflection at the experimental condition, which reveals that no obvious lattice distortions occur. This phenomenon may be true for the relatively lower irradiation fluence or less irradiation area; undoubtedly, the excellent irradiation-resistant property of the alloy may make the alloy sustain less irradiation damage at the experimental condition.

3.3. Nanoindentation. In this study, nanoindentation was performed on pristine and irradiated samples using a G200 nanoindenter system with a Berkovich-type indentation tip. 5 single indents were performed for each 


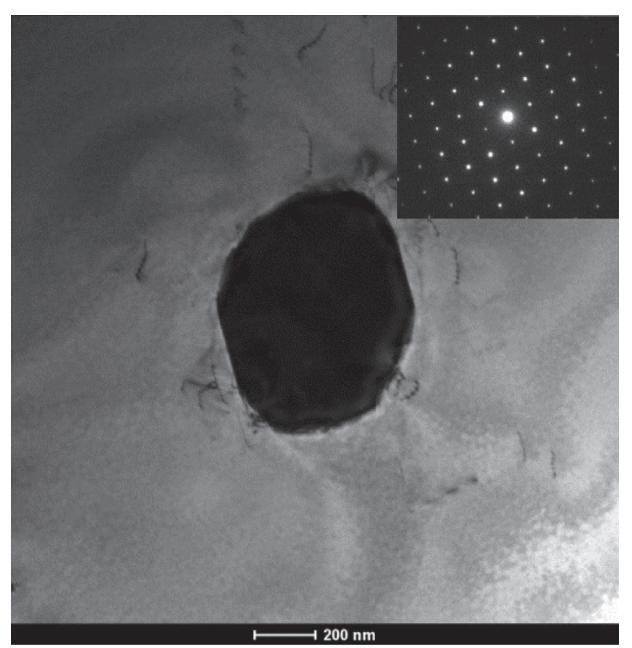

(a)

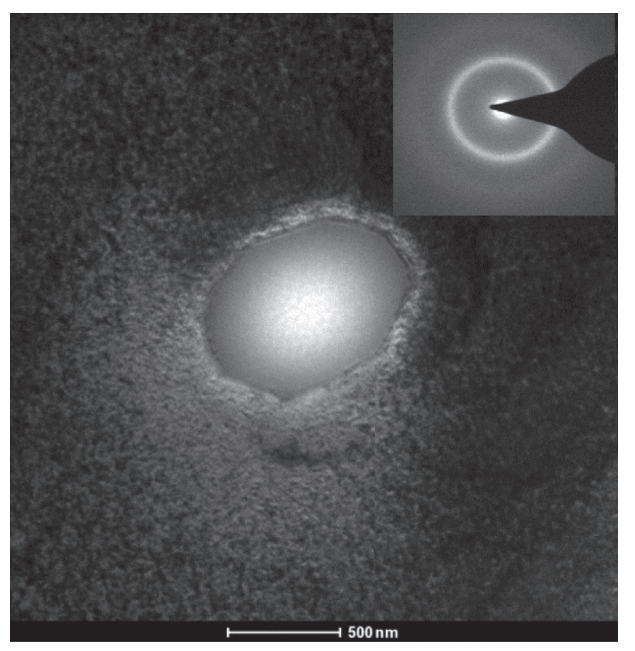

(c)

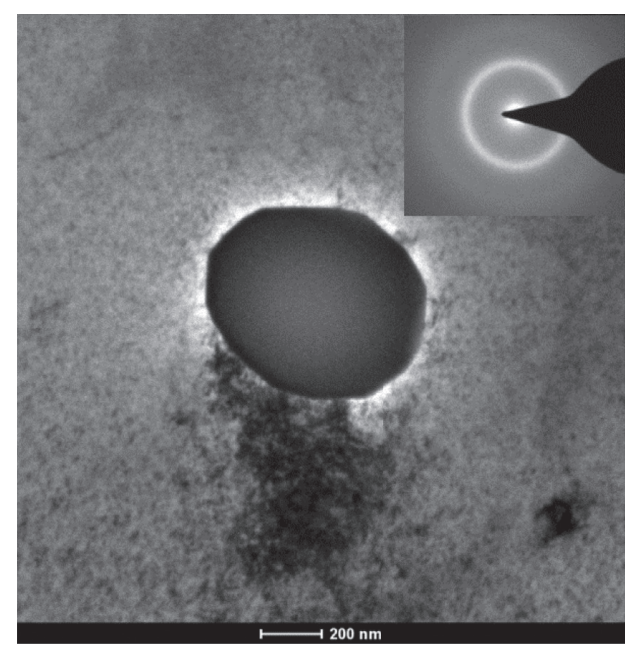

(b)

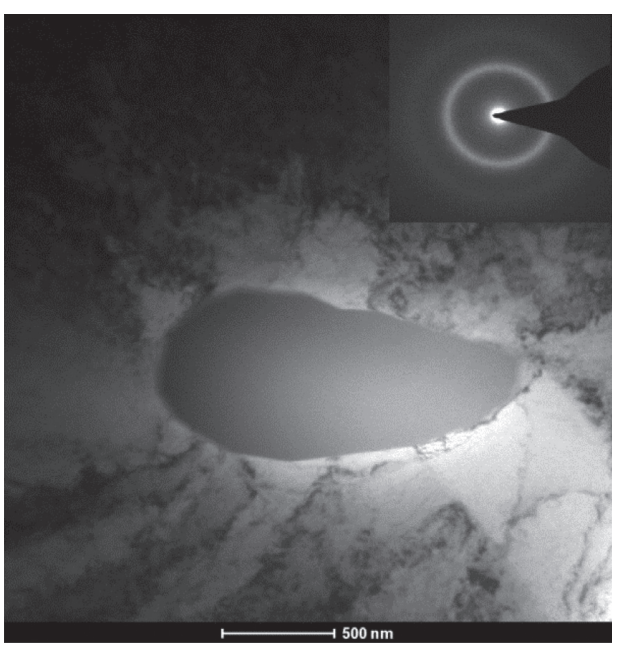

(d)

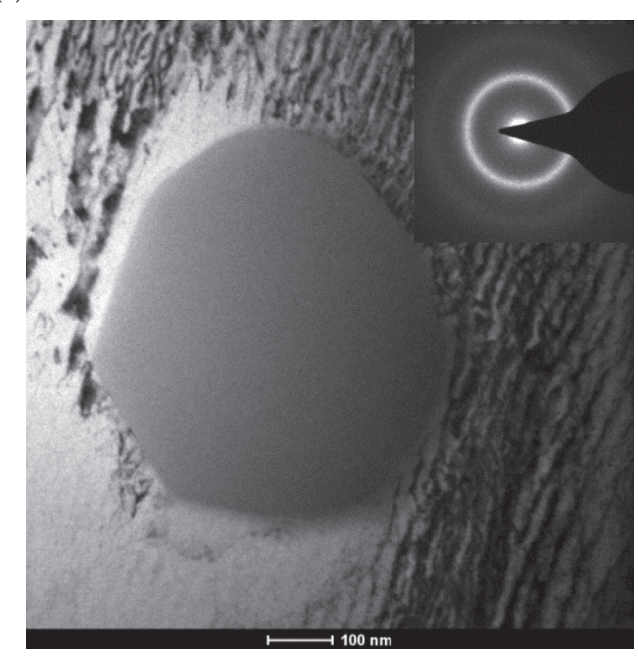

(e)

FIgure 4: Phases in Hastelloy $\mathrm{N}$ alloy before and after ion irradiation: (a) $0 \mathrm{dPa}$, (b) $0.5 \mathrm{dPa}$, (c) $2 \mathrm{dPa}$, (d) $5 \mathrm{dPa}$, and (e) $10 \mathrm{dPa}$. 

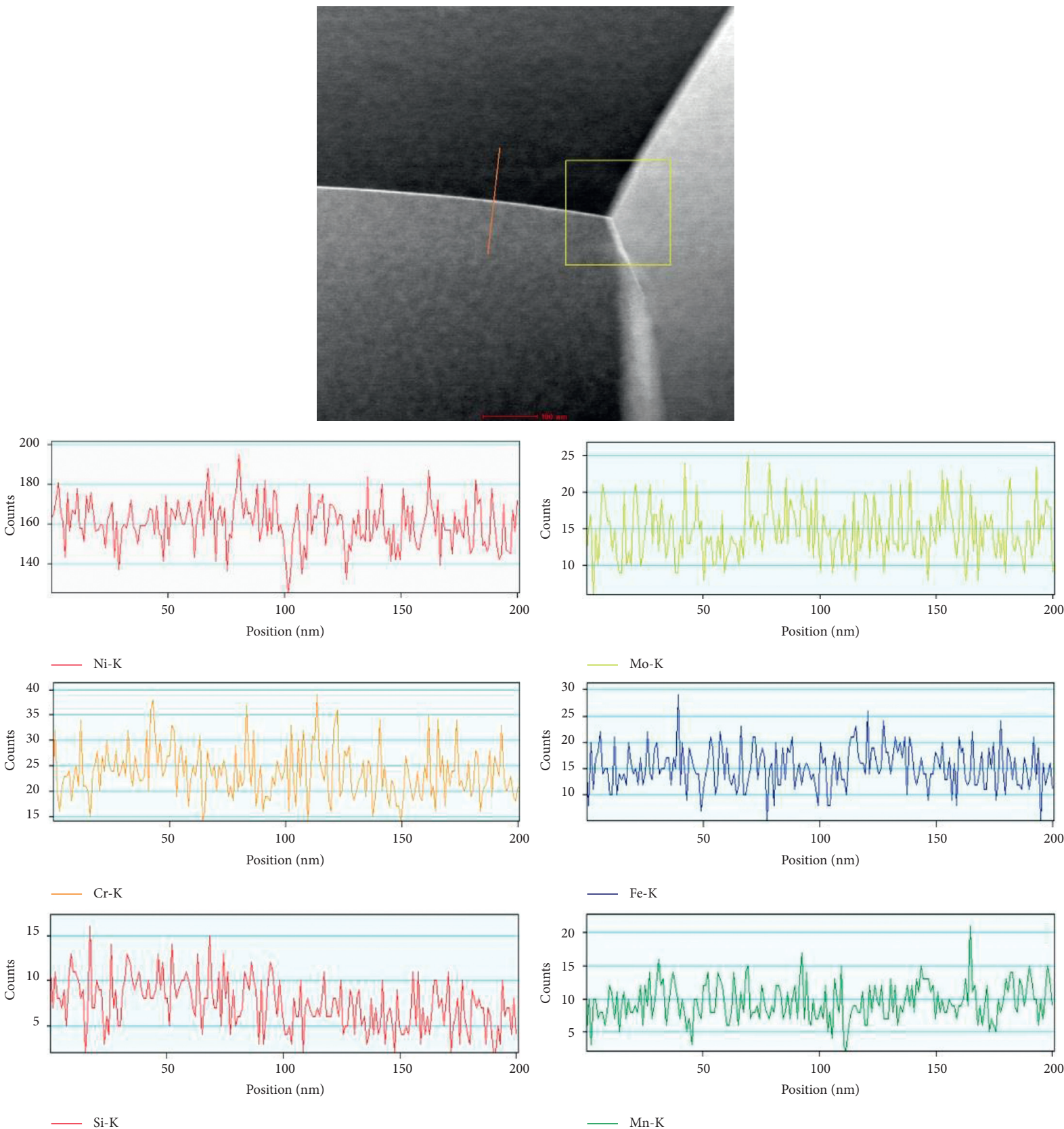

FIgURE 5: Distribution of elements near the grain boundary of the un-irradiated Hastelloy N.

sample to ensure the reliability of the measurements. T hardness of the samples gradually decreased with increasing indentation depth as clearly observed in Figure 10. In light of the presence of strain rate effects around the tip, the uncertainty in the indenter tip geometry, and other surface artifacts such as surface contamination films [32-34], the data in the depth lower than $200 \mathrm{~nm}$ were ignored. In the depth larger than $200 \mathrm{~nm}$, the nanohardness decreased slightly with penetration depth. This can be explained by the Nix-Gao model [35] which predicts the hardness-depth profile to obey the following equation:

$$
H=H_{0} \sqrt{1+\frac{h^{*}}{h}},
$$

where $H_{0}$ is the hardness at infinite depth and $h^{*}$ is a characteristic length which depends on the material and the shape of the indenter tip. $h^{*}$ can be considered as a constant for a given material and indenter. From this equation, it is quite clear that as the indentation depth $(h)$ increases, the measured hardness value decreases gradually and finally approaches $H_{0}$, which is consistent with results in Figure 10 .

The hardness of Hastelloy $\mathrm{N}$ alloy gradually increased with the increase in ion irradiation fluence. Compared to the 

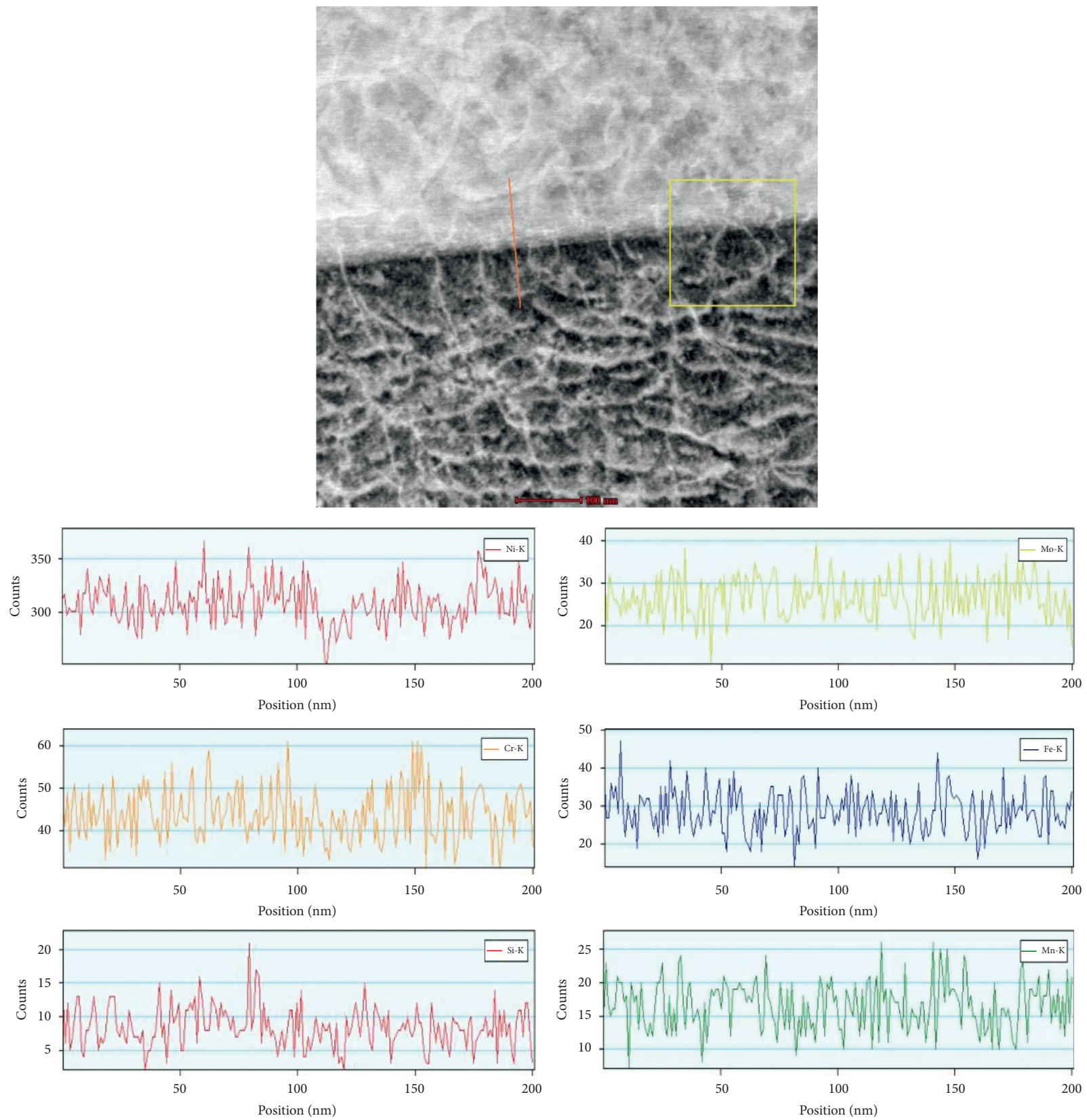

Figure 6: Distribution of elements near the grain boundary of Hastelloy $\mathrm{N}$ after irradiation (10 dPa).

un-irradiated sample, the irradiated Hastelloy $\mathrm{N}$ alloy samples showed an evident hardening phenomenon. In order to get more insight into the changing trend of the hardness with the irradiation fluence, the average hardness of the five groups of different samples before and after irradiation in the range of 200 to $1600 \mathrm{~nm}$ was calculated. The results are shown in Figure 11. The hardness of the Hastelloy $\mathrm{N}$ alloy sample increased rapidly after being irradiated to $0.5 \mathrm{dPa}$, then increased slowly after irradiating from above $0.5 \mathrm{dPa}$ to $5 \mathrm{dPa}$, and remained constant in the samples irradiated to an irradiation fluence equivalent to above 5 to $10 \mathrm{dPa}$. When the irradiation damage fluence was in the range of $5-10 \mathrm{dPa}$, the relation curve between the hardness and the depth basically coincided, indicating that there was a hardening saturation phenomenon. These results are similar to the results reported by Chen et al. [35].

During the ion irradiation process, the bombardment of the surface of the material by high-energy particles forms a cascading collision near the surface of the material, which promotes the formation of a large number of supersaturated point defects (vacancies and interstitial atoms) inside the material [36]. It should be emphasized that most of the point defects disappear in a few picoseconds due to recombination and the remaining point defects will exist in the material in the form of monomers or fine clusters, respectively. The presence of these clusters has a pinning effect on the movement of dislocation lines inside the material resulting in an increase in the hardness of the 

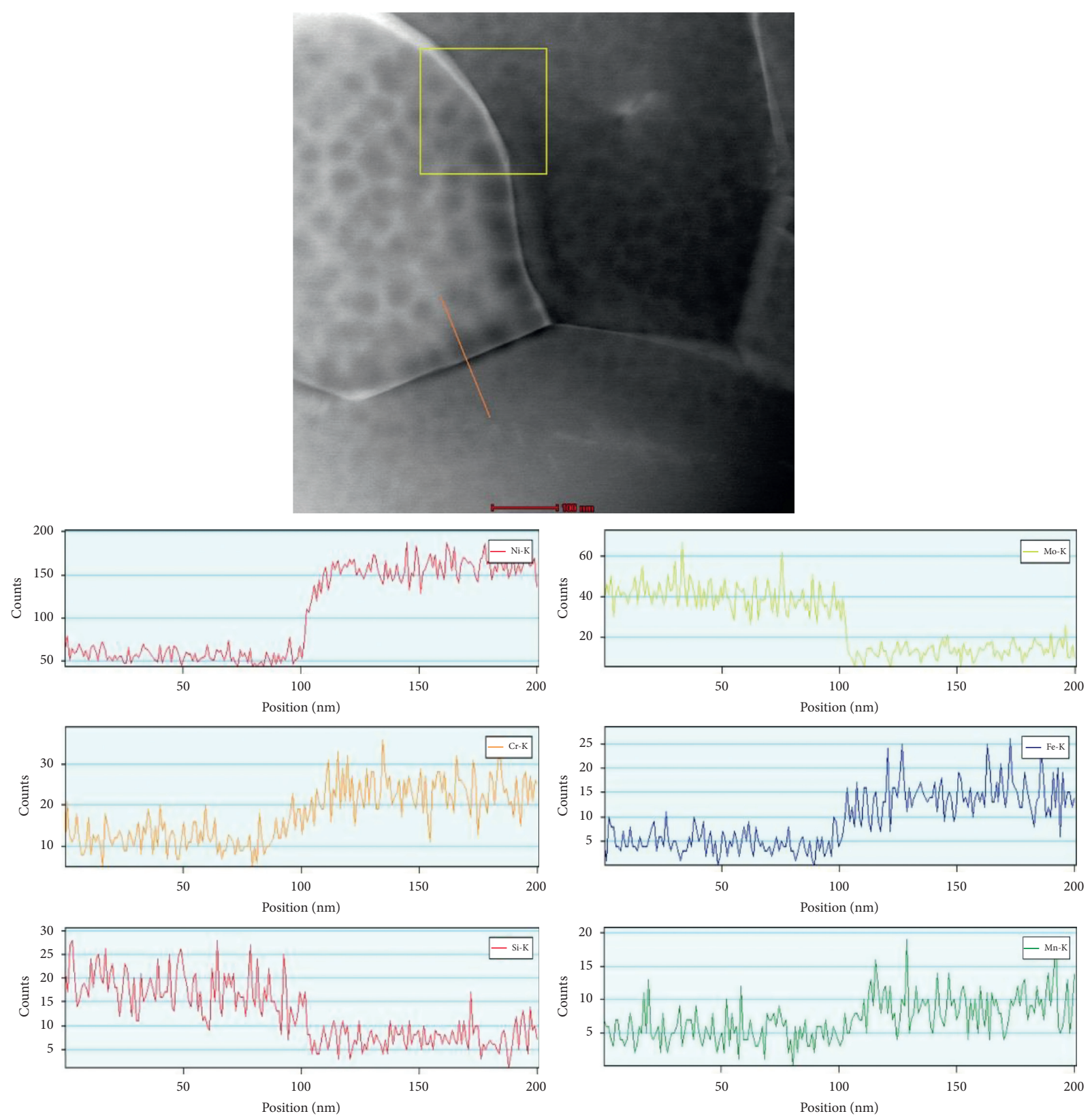

FIgURE 7: Distribution of elements in the second phase and Hastelloy $\mathrm{N}$ matrix.

material $[37,38]$. Theoretically, as the irradiation fluence increases, the supersaturated point defects generated by the cascade of collisions inside the material gradually increase together with the density of the clusters resulting in the gradual increase in the hardness of the material. In this study, the hardness of the Hastelloy $\mathrm{N}$ alloy sample did not change after the ion irradiation from $5 \mathrm{dPa}$ to $10 \mathrm{dPa}$. The reason may be that the Hastelloy $\mathrm{N}$ alloy did indeed produce more irradiation damage at $10 \mathrm{dPa}$ than $5 \mathrm{dPa}$. However, as the concentration of point defects increases, the diffusion rate also increases accordingly, so that the probability of annihilation of vacancies and interstitial atoms increases resulting in a low number of final point defects remaining in the material irradiated to a fluence of $10 \mathrm{dPa}$. Hence, the defects are at the same level as in samples irradiated to $5 \mathrm{dPa}$ so that the hardness of the material remains unchanged under these two irradiation fluences.

It is worth noting that there was no formation of voids observed in the samples irradiated to different fluences at $\mathrm{RT}$. In light of the statistical thermodynamic analysis in the literature [39], it is necessary to reach a critical vacancy concentration depending on the nucleation size of a void and the temperature for void nucleation. The no-void formation observed in this study may be attributed to the irradiation temperature, which is room temperature. 


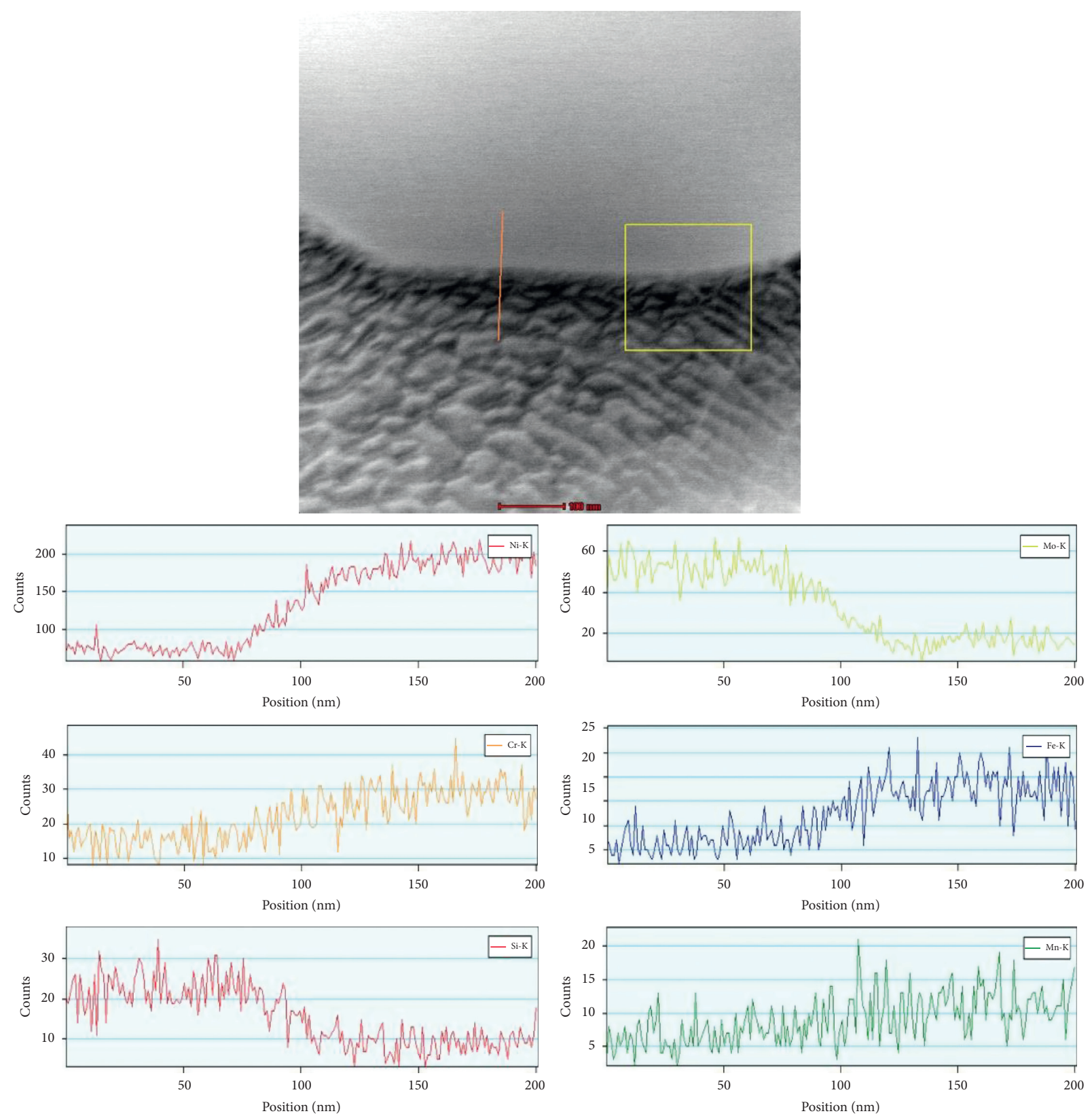

Figure 8: Distribution of elements in the second phase and Hastelloy $\mathrm{N}$ matrix after irradiation (10 dPa). 


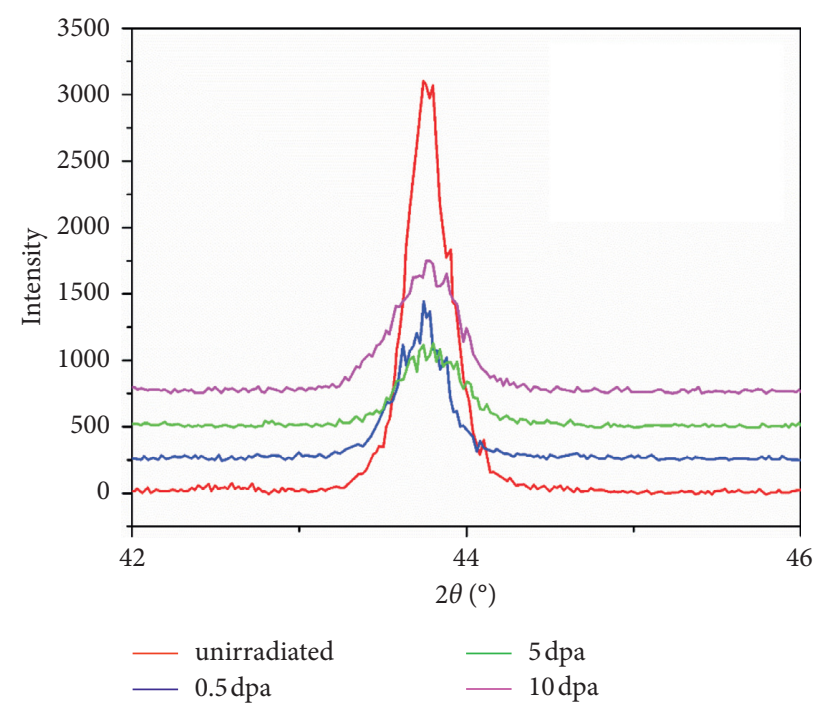

Figure 9: Diffraction pattern of Hastelloy N alloy before and after Xe ion irradiation (enlarged view of the strongest matrix diffraction peak).

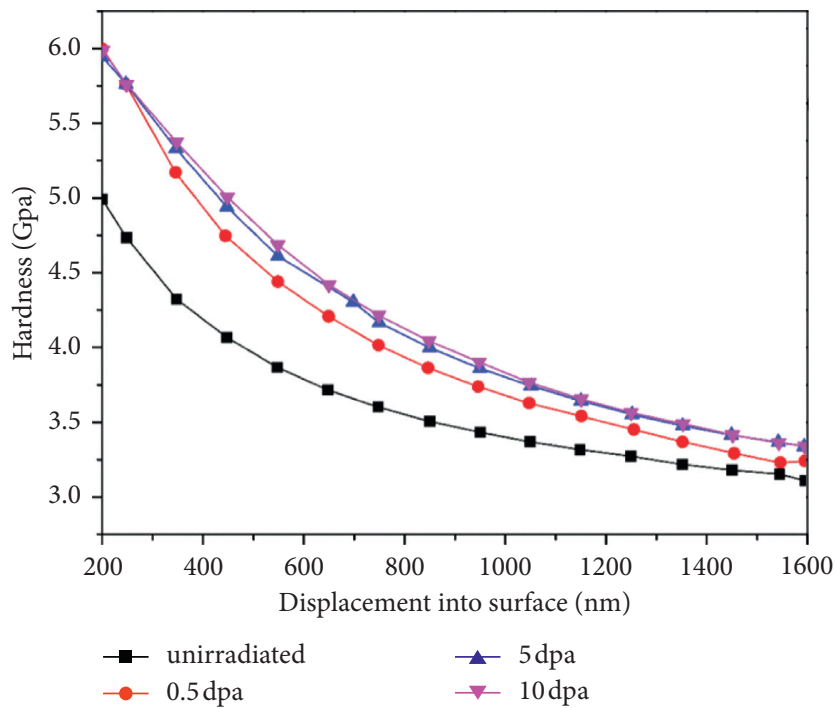

FIgURE 10: Variation curve of the hardness of Hastelloy $\mathrm{N}$ alloy specimen before and after ion irradiation.

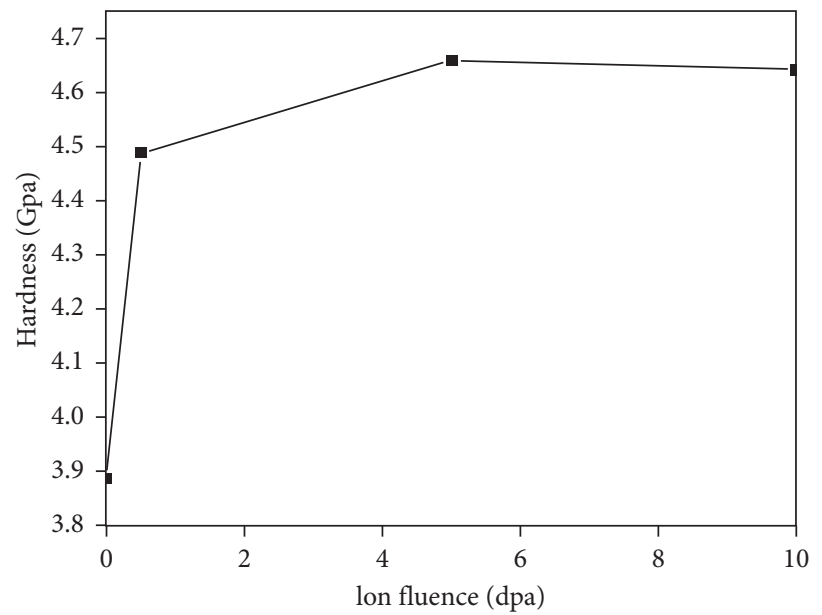

Figure 11: Trend of the average hardness value of Hastelloy $\mathrm{N}$ alloy samples in the depth range of $200-1600 \mathrm{~nm}$ before and after ion irradiation to different fluences. 
Generally, the temperature of irradiation-induced void formation is about $0.3-0.55 T_{\mathrm{m}}$ ( $T_{\mathrm{m}}$ is the melting point) [40-44], and due to the fact that the $T_{\mathrm{m}}$ of Hastelloy $\mathrm{N}$ alloy is about $1400^{\circ} \mathrm{C}$, the void is formed at about $400-700^{\circ} \mathrm{C}$.

\section{Conclusion}

This study was set out to investigate the Xe ion irradiationinduced microstructural evolution and hardening in Hastelloy $\mathrm{N}$ alloy:

(1) A large number of defects were caused by Xe ion irradiation inside the Hastelloy $\mathrm{N}$ alloy, such as black spots and corrugated structures. The corrugated structure formation was the final stage, and the element segregation was found in the corrugated structures.

(2) The second phase in Hastelloy $\mathrm{N}$ alloy is a facecentered cubic structure, with the lattice constant $a=1.09 \mathrm{~nm}$, and it can be rapidly amorphized after being irradiated to $0.5 \mathrm{dPa}$. The second phase was enriched with $\mathrm{Mo}, \mathrm{Si}, \mathrm{Ni}, \mathrm{Fe}$, and $\mathrm{Cr}$.

(3) Segregation of grain boundary elements was not observed in Hastelloy $\mathrm{N}$ alloy before and after irradiation in this study.

(4) Irradiation hardness was found in the Hastelloy $\mathrm{N}$ alloy, which increased with increase in irradiation fluence. The irradiation-induced hardening initiated at low ion fluence $(0.5 \mathrm{dPa})$ and then saturated at a higher ion fluence in the range of 5 to $10 \mathrm{dPa}$.

\section{Data Availability}

The data used to support the findings of this study are available from the corresponding author upon request.

\section{Conflicts of Interest}

The authors declare that they have no conflicts of interest.

\section{Acknowledgments}

This work was supported by the National Natural Science Foundation of China (Grant no. 11605271) and the Youth Innovation Promotion Association, Chinese Academy of Sciences (Grant no. 2016239). The authors are grateful to the Institute of Modern Physics, Chinese Academy of Sciences (IMP-CAS), for providing the platform for ion irradiation experiments.

\section{References}

[1] P. Yvon and F. Carré, "Structural materials challenges for advanced reactor systems," Journal of Nuclear Materials, vol. 385, no. 2, pp. 217-222, 2009.

[2] M. W. Rosenthal, P. N. Haubenreich, and R. B. Briggs, "The development status of molten-salt breeder reactors," Oak Ridge National Laboratory, vol. 4812, 1962.

[3] W. G. Liu, H. Han, C. L. Ren et al., "The effect of $\mathrm{Nb}$ additive on Te-induced stress corrosion cracking in Ni alloy: a first- principles calculation," Nuclear Science and Techniques, vol. 25, no. 05, pp. 92-96, 2014.

[4] L. C. Olson, J. W. Ambrosek, K. Sridharan, M. H. Anderson, and T. R. Allen, "Materials corrosion in molten LiF-NaF-KF salt," Journal of Fluorine Chemistry, vol. 130, no. 1, pp. 67-73, 2009.

[5] A. Nuttin, D. Heuer, A. Billebaud et al., "Potential of thorium molten salt reactorsdetailed calculations and concept evolution with a view to large scale energy production," Progress in Nuclear Energy, vol. 46, no. 1, pp. 77-99, 2005.

[6] L. Mathieu, D. Heuer, R. Brissot et al., "The thorium molten salt reactor: moving on from the MSBR," Progress in Nuclear Energy, vol. 48, no. 7, pp. 664-679, 2006.

[7] S. J. Zhang, D. H. Li, H. C. Chen et al., "Ion irradiation-induced swelling and hardening effect of Hastelloy $\mathrm{N}$ alloy," Journal of Nuclear Materials, vol. 489, pp. 180-186, 2017.

[8] H. Huang, J. Gao, B. Radiguet et al., "Microstructural evolution and hardening of GH3535 alloy under energetic Xe ion irradiation at room temperature and $650^{\circ} \mathrm{C}$," Journal of $\mathrm{Nu}$ clear Materials, vol. 499, pp. 431-439, 2018.

[9] D. Leblanc, "Molten salt reactors: a new beginning for an old idea," Nuclear Engineering and Design, vol. 240, no. 6, pp. 1644-1656, 2010.

[10] M. M. Ghoneim and F. H. Hammad, "Pressure vessel steels: influence of chemical composition on irradiation sensitivity," International Journal of Pressure Vessels and Piping, vol. 74, no. 3, pp. 189-198, 1997.

[11] H. F. Huang, PHD Thesis, University of Rouen, Mont-SaintAignan, France, 2012.

[12] S. M. Bruemmer, E. P. Simonen, P. M. Scott, P. L. Andresen, G. S. Was, and J. L. Nelson, "Radiation-induced material changes and susceptibility to intergranular failure of lightwater-reactor core internals," Journal of Nuclear Materials, vol. 274, no. 3, pp. 299-314, 1999.

[13] S. X. Jin, L. P. Guo, Z. Yang et al., "Microstructural evolution in nickel alloy C-276 after Ar+ ion irradiation," Nuclear Instruments and Methods in Physics Research Section B: Beam Interactions with Materials and Atoms, vol. 269, no. 3, pp. 209-215, 2011.

[14] H. K. Zhang, Z. W. Yao, C. Judge, and M. Griffiths, "Microstructural evolution of CANDU spacer material Inconel X-750 under in situ ion irradiation," Journal of Nuclear Materials, vol. 443, no. 1-3, pp. 49-58, 2013.

[15] H. F. Huang, J. J. Li, D. H. Li et al., "TEM, XRD and nanoindentation characterization of Xenon ion irradiation damage in austenitic stainless steels," Journal of Nuclear Materials, vol. 454, no. 1-3, pp. 168-172, 2014.

[16] E. Getto, Z. Jiao, A. M. Monterrosa, K. Sun, and G. S. Was, "Effect of irradiation mode on the microstructure of self-ion irradiated ferritic-martensitic alloys," Journal of Nuclear Materials, vol. 465, pp. 116-126, 2015.

[17] K. Jin, H. Bei, and Y. Zhang, "Ion irradiation induced defect evolution in Ni and Ni-based FCC equiatomic binary alloys," Journal of Nuclear Materials, vol. 471, pp. 193-199, 2016.

[18] M. Desormeaux, B. Rouxel, A. T. Motta et al., "Development of radiation damage during in-situ $\mathrm{Kr}++$ irradiation of $\mathrm{Fe} \mathrm{Ni}$ Cr model austenitic steels," Journal of Nuclear Materials, vol. 475, pp. 156-167, 2016.

[19] X. Y. Chen, A. L. Wen, C. L. Ren et al., "Theoretical prediction of radiation-enhanced diffusion behavior in nickel under selfion irradiation," Nuclear Science and Techniques, vol. 31, no. 8, pp. 53-63, 2020.

[20] C. Heintze, F. Bergner, and M. Hernández-Mayoral, "Ionirradiation-induced damage in $\mathrm{Fe}-\mathrm{Cr}$ alloys characterized by 
nanoindentation," Journal of Nuclear Materials, vol. 417, no. 1-3, pp. 980-983, 2011.

[21] P. P. Liu, F. R. Wan, and Q. Zhan, "A model to evaluate the nano-indentation hardness of ion-irradiated materials," $\mathrm{Nu}$ clear Instruments and Methods in Physics Research Section B: Beam Interactions with Materials and Atoms, vol. 342, pp. 13-18, 2015.

[22] X. B. Liu, R. S. Wang, A. Ren et al., "Evaluation of radiation hardening in ion-irradiated Fe based alloys by nanoindentation," Journal of Nuclear Materials, vol. 444, no. 1-3, pp. 1-6, 2014.

[23] J. F. Ziegler, M. D. Ziegler, and J. P. Biersack, "Srim-the stopping and range of ions in matter," Nuclear Instruments and Methods in Physics Research Section B: Beam Interactions with Materials and Atoms, vol. 268, no. 11-12, pp. 1818-1823, 2010.

[24] W. C. Olivier and G. M. Pharr, "An improved technique for determining hardness and elastic modulus using load and displacement sensing indentation experiments," Journal of Materials Research, vol. 7, no. 6, pp. 1564-1583, 1992.

[25] W. C. Olivier and G. M. Pharr, "Measurement of hardness and elastic modulus by instrumented indentation: advances in understanding and refinements to methodology," Journal of Materials Research, vol. 19, pp. 3-20, 2004.

[26] F. F. Han, B. M. Zhou, H. F. Huang et al., "The tensile behavior of GH3535 superalloy at elevated temperature," Materials Chemistry and Physics, vol. 182, pp. 22-31, 2016.

[27] B. H. Sencer, G. M. Bond, F. A. Garner et al., "Microstructural evolution of Alloy 718 at high helium and hydrogen generation rates during irradiation with $600-800 \mathrm{MeV}$ protons," Journal of Nuclear Materials, vol. 283-287, pp. 324-328, 2000.

[28] B. H. Sencer, G. M. Bond, F. A. Garner, M. L. Hamilton, S. A. Maloy, and W. F. Sommer, "Correlation of radiationinduced changes in mechanical properties and microstructural development of alloy 718 irradiated with mixed spectra of high-energy protons and spallation neutrons," Journal of Nuclear Materials, vol. 296, no. 1-3, pp. 145-154, 2001.

[29] S. J. Zinkle and Y. Matsukawa, "Observation and analysis of defect cluster production and interactions with dislocations," Journal of Nuclear Materials, vol. 329-333, pp. 88-96, 2004.

[30] S. J. Zinkle, N. Hashimoto, D. T. Hoelzer, A. L. Qualls, T. Muroga, and B. N. Singh, "Effect of periodic temperature variations on the microstructure of neutron-irradiated metals," Journal of Nuclear Materials, vol. 307-311, pp. 192196, 2002.

[31] H. E. McCoy, "An evaluation of the molten salt reactor experiment hastelloy $\mathrm{N}$ survellance specimens-first group," 1967.

[32] Z. Zhu, H. Huang, J. Liu, J. Gao, and Z. Zhu, "Xenon ion irradiation induced hardening in inconel 617 containing experiment and numerical calculation," Journal of Nuclear Materials, vol. 525, pp. 32-39, 2019.

[33] E. H. Lee, Y. Lee, W. C. Oliver, and L. K. Mansur, "Hardness measurements of Ar+-beam treated polyimide by depthsensing ultra low load indentation," Journal of Materials Research, vol. 8, no. 2, pp. 377-387, 1993.

[34] W. D. Nix and H. Gao, "Indentation size effects in crystalline materials: a law for strain gradient plasticity," Journal of the Mechanics and Physics of Solids, vol. 46, no. 3, pp. 411-425, 1998.

[35] H. Chen, Y. Hai, R. Liu et al., "The irradiation hardening of Ni-Mo-Cr and Ni-W-Cr alloy under Xe26+ ion irradiation," Nuclear Instruments and Methods in Physics Research Section
B: Beam Interactions with Materials and Atoms, vol. 421, pp. 50-58, 2018.

[36] A. F. Rowcliffe, L. K. Mansur, D. T. Hoelzer, and R. K. Nanstad, "Perspectives on radiation effects in nickelbase alloys for applications in advanced reactors," Journal of Nuclear Materials, vol. 392, no. 2, pp. 341-352, 2009.

[37] S. Jin, L. Guo, Y. Ren, R. Tang, and Y. Qiao, "TEM characterization of self-ion irradiation damage in nickel-base alloy C-276 at elevated temperature," Journal of Materials Science \& Technology, vol. 28, no. 11, pp. 1039-1045, 2012.

[38] S. Teysseyre, Z. Jiao, E. West, and G. S. Was, "Effect of irradiation on stress corrosion cracking in supercritical water," Journal of Nuclear Materials, vol. 371, no. 1-3, pp. 107-117, 2007.

[39] A. V. Kozlov, I. A. Portnykh, E. A. Kinev, S. V. Bryushkova, and I. A. Portnykh, "The swelling dependence of cold worked $16 \mathrm{Cr}-15 \mathrm{Ni}-2 \mathrm{Mo}-\mathrm{MMn}$ steel on neutron irradiation temperature, fluence and damage rate during its use as a cladding material in the BN-600 reactor," in Proceedings of the 2001 International Symposium on Irradiation Effect on Materials ASTM-20, pp. 457-468, West Conshohocken, PA, USA, 2001.

[40] S. Jin, X. He, T. Li, S. Ma, R. Tang, and L. Guo, "Microstructural evolution in nickel alloy C-276 after Ar-ion irradiation at elevated temperature," Materials Characterization, vol. 72, pp. 8-14, 2012.

[41] J. F. Bates and R. W. Powell, "Irradiation-induced swelling in commercial alloys," Journal of Nuclear Materials, vol. 102, no. 1-2, pp. 200-213, 1981.

[42] J. F. Stubbins and F. A. Garner, "Swelling and microstructure of high purity nickel irradiated with fast neutrons in EBR-II," Journal of Nuclear Materials, vol. 191-194, pp. 1295-1299, 1992.

[43] N. I. Budylkin, E. G. Mironova, V. M. Chernov, V. A. Krasnoselov, S. I. Porollo, and F. A. Garner, "Neutroninduced swelling and embrittlement of pure iron and pure nickel irradiated in the BN-350 and BOR-60 fast reactors," Journal of Nuclear Materials, vol. 375, no. 3, pp. 359-364, 2008.

[44] S. I. Porollo, A. M. Dvoriashin, Y. V. Konobeev, and F. A. Garner, "Microstructure and swelling of neutron irradiated nickel and binary nickel alloys," Journal of Nuclear Materials, vol. 442, no. 1-3, pp. S809-S812, 2013. 